\title{
Симптоми на ЛОР органите при пациенти с гастроезофагеална рефлуксна болест (ГЕРБ)
}

\author{
М. Пенкова, К. Тенев, П. Димов \\ Клиника по вътрешни болести, Клиника по оториноларингология \\ Университетска болница Стара Загора, \\ Медицински факултет, Тракийски университет - Стара Загора
}

\section{Резюме}

Въведение: Гастроезофагеалната рефлуксна болест (ГЕРБ) се дефинира, като хронично възпаление на долната трета на хранопровода в резултат на връщане на част от стомашното съдържание (а понякога и гастродуоденален рефлукс) към хранопровода и/или в съседни органи (фаринкса, ларинкса, бронхите), което води до променлив спектър от езофагеални и/или извън езофагеални признаци и симптоми, свързани или не с тъканни лезии.

Цел: Да се определи разпространението на някои симптоми в ЛОР органите при пациенти с гастро-езофагеална рефлуксна болест (ГЕРБ).

Материал и методи: Извършено е проучване на 54 пациенти в продължение на 18 месеца. При всички пациенти са осъществени: стандартно изследване на ЛОР органи; изследвания на гастроинтестинален тракт: горна ендоскопия (по Лос Анджелиската класификация, 2003 г.), контрастна рентгенография на хранопровода и стомаха с Бариев сулфат; $\mathrm{pH}$ тест. Резултатите се обработиха в програмата SPSS, версия 10.0.

Резултати: Пациентите с типични симптоми на гастроезофагеална рефлуксна болест бяха 48 (88\%). При двадесет и седем болни се установиха промени в лигавицата на хранопровода - клас А - 27 (50\%), клас Б - 17 (31.5\%) и $10(18.5 \%)$ - от класове C + D. При по-тежки степени на езофагити бяха диагностицирани по-изявени симптоми и промени в устната кухина. Заключение: Нашите резултати, както и на други автори потвърждават, че промените в ЛОР органите при болни с ГЕРБ зависят от степентта на възпалителните промени в хранопровода

Ключови думи: ГЕРБ, симптоми, хроничен ларингит, устна кухина

\section{Въведение}

Гастроезофагеалната рефлуксна болест (ГЕРБ), с различни по степен промени в лигавицата на хранопровода, се причинява от рефлукс на стомашно и дуоденално съдържимо. Това е честа диагноза в клиничната практика. ГЕРБ е сериозен проблем за общественото здраве, защото е хронично протичащо заболяване, с повтарящи се епизоди на обостряне, които нарушават комфорта на живот (1).

Връзката между ГЕРБ и промените в оториноларингологичните (ЛОР) органи се обсъжда от 1960 г. (2). Последните проучвания показват повишена честота на симптоми от страна на ЛОР органите като нетипични прояви на гастроезофагеална рефлуксна болест (3). Ларингофарингеалният рефлукс (ЛФР) възниква при навлизане на стомашно съдьржимо с повишена киселинност в горните дихателни пътища (4). Повечето пациенти с ЛФР нямат класически симптоми на ГЕРБ, като киселини и регургитация (5). В литературата не съществуват много данни, които тьрсят връзка между степента на езофагита и наличието и степента на изразеност на различни симптоми в ЛОР органите. Този въпрос е важен, тъй като определя адекватното лечение и по-бързо и ефективно подобряване на качеството на живот на пациентите.

Целта на проучването е да се определи разпространението на някои симптоми в ЛОР органите при пациенти с различна тежест на ГЕРБ.

\section{Материал и методи}

На всички пациенти (54) беше осьществена горна ендоскопия на храносмилателния тракт. Болните с 
установен ерозивен езофагит бяха класифицирани в съответствие с критериите на Лос Анджелиската класификация 2003 г. (Таблица 1). Стандартен въпросник беше използван за диагноза на ГЕРБ. На болните беше извършен прецизен преглед на ЛОР органите с оценка на симптомите и $\mathrm{pH}$ тест Cybow.

Таблица 1. Лос Анжелиска класификация на ГЕРБ

\begin{tabular}{|l|}
\hline \multicolumn{1}{|c|}{ Лос Анджелиска класификация на ГЕРБ } \\
\hline \multicolumn{1}{|c|}{ Степен A } \\
\hline $\begin{array}{c}\text { Една или повече лезии на лигавицата, не по-големи от } \\
5 \text { мм и запазена лигавица между тях }\end{array}$ \\
\hline \multicolumn{1}{|c|}{ Степен B } \\
\hline $\begin{array}{c}\text { Една или повече лезии на лигавицата, по-големи от } 5 \\
\text { мм , неконфлуиращи помежду си }\end{array}$ \\
\hline \multicolumn{2}{|c|}{ Степен C } \\
\hline $\begin{array}{l}\text { Една или повече лезии на лигавицата, по-големи от } 5 \\
\text { мм , конфлуиращи помежду си , но обхващат не пове- } \\
\text { че от 75\% от циркумференцията на хранопровода }\end{array}$ \\
\hline \multicolumn{2}{|c|}{ Стен } \\
\hline $\begin{array}{l}\text { Една или повече лезии на лигавицата, по-големи от } 5 \\
\text { мм , конфлуиращи помежду си , обхващат повече от } \\
75 \% \text { от циркумференцията на хранопровода, налична } \\
\text { метаплазия на лигавицата тип Барет }\end{array}$ \\
\hline
\end{tabular}

Статистическият анализ бе извършен с програма „SPSS за Windows“. За ниво на статистическа значима стойност бе прието по-малко от $5 \%(\mathrm{p}<0.05)$. Всички пациенти бяха информирани за целта на изследването и дадоха писмено сьгласие за участие.

\section{Резултати}

В проучването бяха включени петдесет и четири $(100 \%)$ пациенти - 28 мъже $(51.8 \%)$ и 26 жени (48.2\%) на средна възраст 47,9 години, варираща между 22 и 65 години.

Болните с типични симптоми на гастроезофагеална рефлуксна болест бяха 48 (88\%), а 6 (12\%) - с атипични симптоми. Пациенти с промени от клас $\mathrm{A}-27$ (50\%), клас Б - 17 (31.5\%) и 10 (18.5\%) бяха пациенти от класове C + D (Фигура 1).

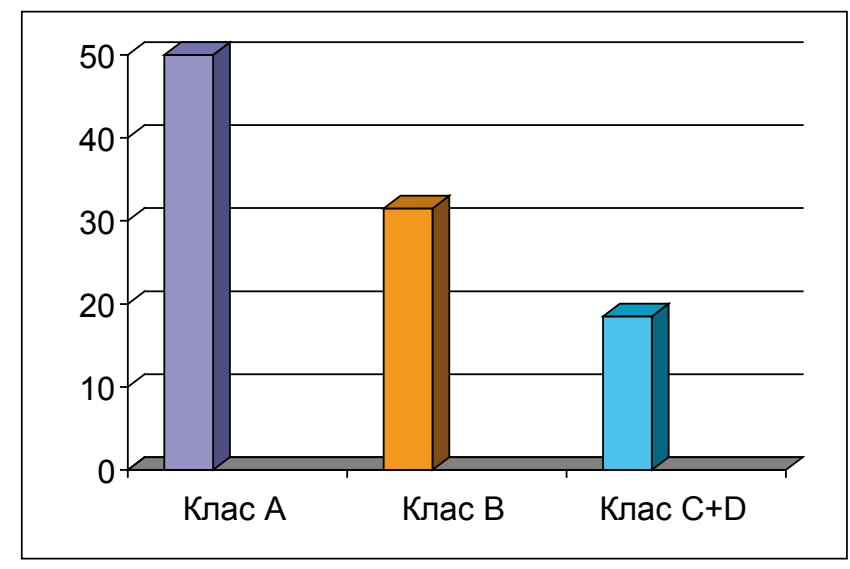

Фиг. 1. Разпределение на пациентите според степен на възпаление на хранопровода по Лос Анджелиската класификация

От проследените 27 (50\%) пациенти, с ендоскопска промени клас А по класификация Лос Анджелис, 15 (55.5\%) бяха без симптоми с нормален ОРЛ статус; 12 (44,5\%) - с типични симптоми за глобус фарингеум, дрезгав глас, суха дразнеща кашлица. Пет $(29,4 \%)$ от пациентите от клас Б 17 $(31.5 \%)$ имаха дрезгав глас с промени на гласните връзки. От Клас С и D бяха диагностицирани 10 пациенти $(18.5 \%)$ - всички с изразени симптоми за хроничен ларингит. Промените в ЛОР органите бяха по-разпространени при по-тежки форми на езофагит (клас C и D) в сравнение с леките форми (класове А и Б) - статистически значима разлика $(\mathrm{p}<0.05)$. При всички пациенти с атипични симптоми 6 (12\%) бе отчетено променено $\mathrm{pH}$ на устната кухина между 4.5 и 5.5 при норма около 7 със стандартен тест Cybow. В таблица 2 са представени най-честите симптоми от ЛОР органите при пациенти с ГЕРБ.

Таблица 2. Установени симптоми при ГЕРБ

\begin{tabular}{|c|c|c|c|c|c|c|}
\hline Симптоми & Дрезгав глас & $\begin{array}{c}\text { Парене в } \\
\text { устата }\end{array}$ & Горчив вкус & $\begin{array}{c}\text { Глобус } \\
\text { фарингеус }\end{array}$ & Суха кашлица & $\begin{array}{c}\text { Ерозии на } \\
\text { зъбите }\end{array}$ \\
\hline $\begin{array}{c}\text { Болни } \\
54(100 \%)\end{array}$ & $51(95 \%)$ & $49(90 \%)$ & $44(82 \%)$ & $50(94 \%)$ & $40(75 \%)$ & $42(78 \%)$ \\
\hline
\end{tabular}

\section{Обсъждане}

Според Американската Бронхоезофагеална асоциация, най-често срещаните симптоми на ЛФР са дрезгавост на гласа (97\%), глобус фарингеус (95\%) и хронична кашлица (95\%) (9). P. Koufman (10) е първият, който прави разлика между ГЕРБ - ЛФР при изследвани на 899 пациенти. Той установява дрезгавост в гласа при $87 \%$ от болните с ЛФР и само при $3 \%$ от болните с ГЕРБ. Подобно на горните автори, нашите резултати потвьрждават наличието на такива симптоми (виж таблица 2). Усещане за киселини установя при $83 \%$ от болни- 
те с ГЕРБ, докато при пациентите с ЛФР симптомът е само $20 \%$ от изследваните. Според С. Ford (4) има три начина да се потвърди ЛФР: 1. подобрение на симптомите след лечение с промени в начина на живот и медикаменти, 2. ендоскопско наблюдение на засегнатата лигавица 3. демонстрация на подобрение в $\mathrm{pH}$ мониторирането в динамика. В друго проучване, публикувано от R.Ylitalo (12) ендоскопските изследвания показват неспецифични симптоми и промени като хиперемия, оток на задната стена на фарингса и ларинкса и др. Цитираният автор счита, че на ендоскопско изследване (с ригиден или гъвкав ларингоскоп) трябва да се подлагат всички пациенти с подозрение за ЛФР (12).

В проучване, направено от Торос и кол. (5) с горна ендоскопия, само $11 \%$ от пациентите със симптоми на ЛФР показват промени, характерни за ГЕРБ.

Повечето автори, както и ние считаме, че когато не се мисли и търси насочено диагнозата ЛФР, пациентите дълго време могат да имат персистиращи оплаквания и забавена епителизация на лигавицата. $(6,8,12)$.

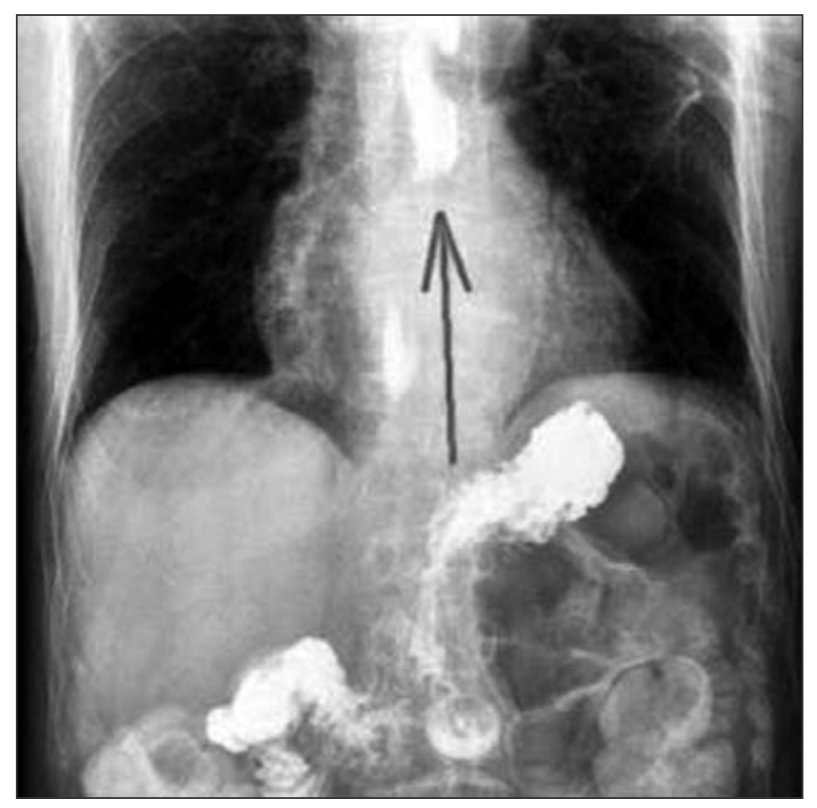

Фиг. 2. Контрастна рентгенография на хранопровод - рефлукс езофагит

\section{Заключение}

В ежедневната лекарска практика симптомите на ГЕРБ все повече изявяват своята клинична картина. Промените в ЛОР органите са честа находка при пациентите с по-висока степен на възпаление на езофагеалната лигавица. За адекватна и прецизна диагноза е необходимо използването на комплексни методи за изследване на горен храносмилателен тракт и ЛОР органи при болни с типични и атипични оплаквания с участието на гастроентеролози, оториноларинголози, стоматолози и др.

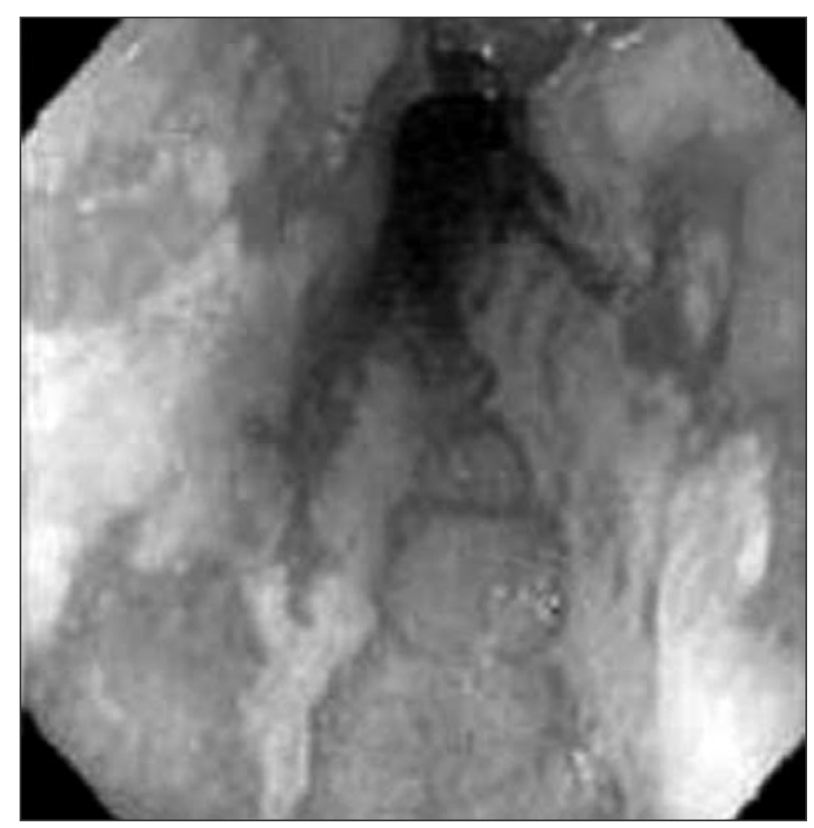

Фиг. 3. Горна ендоскопия - Рефлукс езофрагит

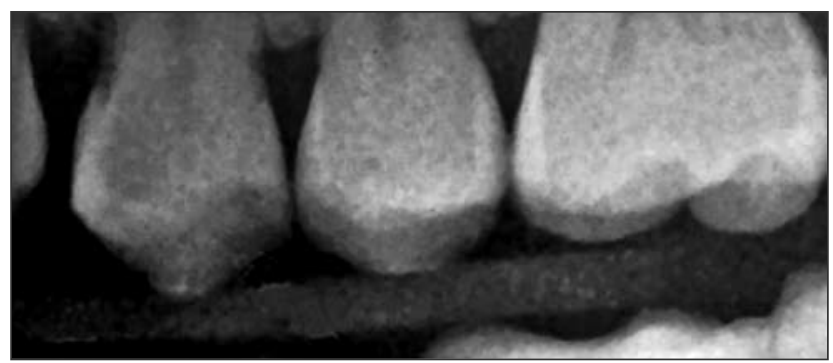

Фиг. 4. Рентгенография на пациент с ерозии на емайла на горните зъби $(3,4,5)$ при рН около 5,5 (при норма в устната кухина 6-8 pH)

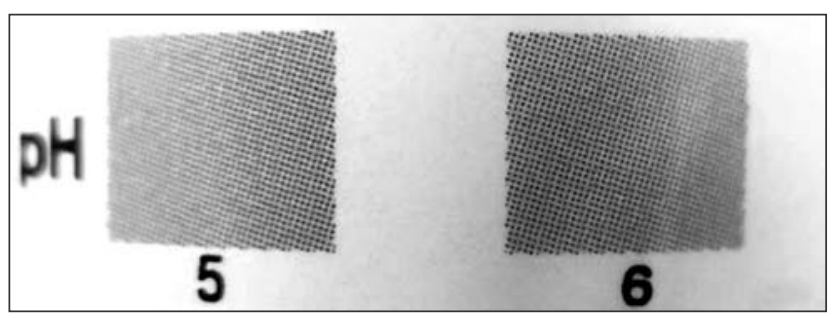

Фиг. 5. рН тест на устна кухина при болен с ГЕРБ 


\section{Литература}

1. Zenev Iv. Burning mouth symptom diagnosis and terapy, Otorhinolaryngology 2004: 5-7

2. arrokhi F, Vaezi MF. Extra-esophageal manifestions of gastroesophageal reflux. Oral Diseases. 2001, 13: 349-59.

3. Ulualp SO, Toohill RJ, Shaker R. Outcomes of acid supressive therapy in patients with posterior laryngitis. Otolaryngol Head Neck Surg. 2001, 124: $16-22$

4. Ford CN. Evaluation and Management of Laryngopharyngeal Reflux. Jama. 2005, 294(12): 1534-1540.

5. Toros et al. Association of laryngopharyngeal manifestions and gastroesophageal reflux. Eur Arch Otorhinolaryngol. 2009, 266:403-9. 6. Barbuti RC, Moraes-Filho JPP. Doença do Refluxo Gastroesofágico. Gastroenterologia Medsi. 2004, 119-128.

7. Dent J. et al. An evid.ence-based appraisal of reflux disease management - the Genval Workshop Report. GUT. 1999, 44(2): S1-S16.
8. Pribuisene R, Uloza V, Jonaitis L. Typical and atypical symptoms of laryngopharyngeal reflux disease. Medicina. 2002, 38(7): 699-705.

9. Book DT, et al. Perspectives in laryngopharyngeal reflux: an international survey. Laryngoscope. 2002, 16: 274-277.

10. Koufman JA. The otolaryngologic manifestations of gastroesophageal reflux disease (GERD): a clinical investigation of 225 patients using ambulatory 24-hour $\mathrm{pH}$ monitoring and an experimental investigation of the role of acid and pepsin in the development os laryngeal injury. Laryngoscope. 1991, 101: 01-78.

11. Vaezi MF. Laryngitis and gastroesophageal reflux disease: increasing prevalence or poor diagnostic tests? Am J Gastroenterol. 2004, 99: 1000-1010.

12. Ylitalo R, Lindestad P, Ramel S. Symptoms, laryngeal findings, and 24-hour $\mathrm{pH}$ monitoring in patients with suspected gastroesophago-pharyngeal reflux. Laryngoscope. 2001, 111: 1735-1741. 